\title{
PREPARATION METHOD OF NZVI-PVDF HYBRID FILMS WITH CATION- EXCHANGE FUNCTION FOR REDUCTIVE TRANSFORMATION OF CR(VI)
}

\author{
Xiangyu WANG ${ }^{*}$, Shan CONG \\ Faculty of Environmental Science and Engineering, Kunming University of Science and Technology, \\ 650500, Kunming, China
}

Received 06 February 2017; accepted 02 June 2017

\begin{abstract}
Poly (vinylidene fluoride) (PVDF) microporous film was successfully synthesized and functionalized by poly acrylic acid (PAA) for immobilization of nanoscale zero-valent iron (NZVI). PAA was innovatively introduced onto PVDF film via in situ polymerization of acrylic acid (AA) and followed by ion exchange procedure. The as-prepared PAA/PVDFNZVI hybrids (PPN) were characterized in terms of morphology (SEM) and surface functional groups (FTIR). FTIR spectra confirms the functionalization of PVDF film by coating of PAA within its micropores. And SEM images suggested that NZVI were well immobilized onto the surface of the support. Over the reaction course, the resultant PPN hybrids demonstrated high reactivity, excellent stability and reusability for $\mathrm{Cr}(\mathrm{VI})$ removal. Results showed that lower $\mathrm{pH}$ and initial concentration facilitated the removal of Cr(VI) by PPN. Compared with bare NZVI, PAA/PVDF film-immobilized NZVI resulted in a lower activation energy for $\mathrm{Cr}(\mathrm{VI})$ removal, indicating that $\mathrm{Cr}(\mathrm{VI})$ reduction process with $\mathrm{PPN}$ is a surfacecontrolled chemical reaction. Moreover, a two-parameter pseudo-first-order model was provided and well-described the reaction kinetics of $\mathrm{Cr}(\mathrm{VI})$ over PPN under various conditions.
\end{abstract}

Keywords: polyvinylidene fluoride, cation exchange function, hydrophilization, $\mathrm{Cr}(\mathrm{VI})$ removal, nanoscale zero-valent iron, revised kinetics, wastewater management.

\section{Introduction}

The widespread use of toxic heavy metals in industrial processes constitutes the primary source for water pollution and it's accumulating in the ecosystem causes serious risk to the environment and the living systems. Chromium, a common heavy metal contaminant, universally exists in soils, groundwater, and surface waters in trivalent and hexavalent forms with the widespread use in industrial processes, such as electroplating, metallurgy, leather tanning, and textile dying industries (Bhattacharya et al. 2014; Shen et al. 2010; Mu et al. 2015a; Zaleckas et al. 2013). $\mathrm{Cr}(\mathrm{III})$ is relatively harmless and immobile with a trace concentrations because it is needed for glucose metabolism in human nutrition as well as for plants and animals, whereas $\mathrm{Cr}(\mathrm{VI})$ is more toxic and moves through aquatic environments (Cao, Zhang 2006; Chen et al. 2015; Fang et al. 2011a). $\mathrm{Cr}(\mathrm{VI})$ with the property of being strong oxidizing agent, which can be absorbed to human body and result in inherited gene defects, cancer, and even death due to its detrimental characteristics such as carcinogenicity, mutagenicity, and teratogenicity (Shen et al. 2010; Kim et al. 2015; Li et al. 2008). Thus, everincreasing endeavors have been devoted to investigate the reduction of $\mathrm{Cr}(\mathrm{VI})$ to $\mathrm{Cr}(\mathrm{III})$ because it is a feasible method for removal of $\mathrm{Cr}(\mathrm{VI})$.

Engineered nanomaterials are newly developed for $\mathrm{Cr}(\mathrm{VI})$ removal, by which $\mathrm{Cr}(\mathrm{VI})$ was reduced, immobilized, and further removed by precipitation ( $\mathrm{Mu}$ et al. 2015a, 2015b; Fang et al. 2011a). As a reductive material, nanoscale zero-valent iron (NZVI) has been used increasingly for removing a wide variety of pollutants including $\mathrm{Cr}$ (VI) over the last decade (Xu, Wang 2011; Kim et al. 2008; Ling et al. 2015). Due to its excellent physical and chemical properties (including large specific surface area, high reactivity, and low-cost), NZVI was chosen to be remediation agent for treatment of $\mathrm{Cr}(\mathrm{VI})$ wastewater. The NZVI particles reduce toxic heavy metals through oxidation of the $\mathrm{Fe}^{0}$ core and subsequent allocation of electrons to the pollutant at a relatively fast reaction rate because of its larger specific surface area and higher surface reactivity (Wang et al. 2008; Shu et al. 2007, 2010; Shih et al. 2011; Qiu et al. 2013). Although NZVI

*Corresponding author. E-mail: imusthlee2014@sina.com 
is very effective for environmental remediation, the agglomeration and instability of NZVI in the preparation and application process might diminish its reactivity. To obtain more physical stable NZVI particles, surfactants, starch, chitosan, carboxymethyl cellulose, resin, activated carbon, and microfiltration films have been studied as dispersant or support for preparing NZVI particles in aqueous media (Horzum et al. 2013; Lin et al. 2009; Lv et al. 2012; Meng et al. 2011). In addition, accompanying the increasing application of NZVI particles, more and more nanoparticles have been released into the aqueous environment and brought potential harmful impact on indigenous organisms, thus a new problem emerged, that of the nanotoxicity. However, the common dispersant did not play the role of preventing the release of nanoparticles into the environment. To overcome the aforementioned problems, the preparation method of NZVI-PVDF hybrid films with cation-exchange function was provided in this study for reductive transformation of $\mathrm{Cr}(\mathrm{VI})$.

As an alternative, NZVI particles supported on a special hybrid film may offer a successful resolution to this problem, because this material will (1) reserve NZVI particles in the film to avoid the risk for ecosystem, (2) be an ideal reaction media for controlling agglomerated and monodisperse nanoparticles, and (3) reduce material waste with its own performance of reusability (Wang et al. 2008; Yang et al. 2014). Polyvinylidene fluoride (PVDF) microfiltration films has been intensively studied for its applications to water and wastewater treatment in recent years (Byun et al. 2013; Li et al. 2010, 2013; Oh et al. 2009; Dong et al. 2013) for their open structure, $100-500 \mathrm{~nm}$ pore size, mechanical strength, and chemical stability, while showing no adsorption of metal ions (Xia et al. 2012; Fang et al. 2015). Researchers managed to immobilize nano particles in ion exchange (chelating) modified film to capture metal cation (Wang et al. 2008). Consequently, the secondary pollution can be avoided due to the ability of chelating to recapture the metal ions released after reaction, and the reuse of film is possible. Therefore, it is necessary to further investigate the activity of various types of NZVI-PVDF composite film for removal of different pollutants.

We aim to design an effective method for preparation and immobilization of NZVI at low-cost, with easy operation and environmental-friendliness. In this regard, poly acrylic acid (PAA) coating layer on the laboratorysynthesized support PVDF film was obtained by in situ polymerization of acrylic acid, contains carboxylic acid groups that can bind cations via ion exchange, chelation and static binding. After being functionalized by PAA, a nanoscale reactor was installed and NZVI particles were immobilized inside it. The objectives of current study are: (1) to fabricate PAA/PVDF-NZVI (PPN) hybrids for investigation of their reactivity toward heavy metals by using $\mathrm{Cr}(\mathrm{VI})$ as a model; (2) to evaluate their efficiency for $\mathrm{Cr}(\mathrm{VI})$ removal under different $\mathrm{Cr}(\mathrm{VI})$ concentrations, $\mathrm{pH}$ values, and solution temperatures; (3) to calculate the activation energies of pristine NZVI and PPN hybrids to further study the reduction of $\mathrm{Cr}(\mathrm{VI})$; (4) to provide an innovatively revised kinetic and the possible transformation pathway of $\mathrm{Cr}(\mathrm{VI})$ by PPN hybrids. Considering these objectives, synthetic procedures, characterization, and discussion on the possible mechanism for the reduction of $\mathrm{Cr}(\mathrm{VI})$ by PPN will be presented.

\section{Materials and methods}

\subsection{Materials}

PVDF (FR 904, MW: 600,000) was supplied by Shanghai 3F New Materials Co. Ltd. China. Acrylic acid (AA, $>99.5 \%$ ) was obtained from Tianjin Yongda Stainless Steel Co., Ltd. Ethylene glycol (EG, >99\%), ferrous sulfate heptahydrate and potassium borohydride were supplied by Chengdu KeLong Chemical Co,. Ltd. Polyvinylpyrrolidone (PVP), dimethylacetamide (DMAc), ammonium persulfate (APS) and a mixture of ultrapure (UP) water (resistivity $>18.25 \mathrm{M} \Omega \mathrm{cm}$ ) and ethanol were used as the non-solvents in the polymer precipitation. All chemicals in this study were obtained from Sinopharm Chemical Reagent Co., Ltd (China). All chemicals were used as received without further purification unless otherwise mentioned.

\subsection{Preparation of PVDF microporous film}

The phase-inversion method was used to prepare PVDF support film. PVDF (10\%, wt.\%) was dissolved into DMAc solvent at $298 \mathrm{~K}$. Subsequently, PVP used in pore-forming were simultaneously introduced into the solvent, followed by vigorous magnetic stirring for at least $12 \mathrm{~h}$ for complete admixture. The casting polymer solution was deposited undisturbed for $24 \mathrm{~h}$ to take air bubbles away. To prepare a uniform liquid film, an appropriate amount of the casting polymer solution was uniformly dispersed on a glass plate at room temperature and $60 \%$ humidity. After exposed to air for $50 \mathrm{~s}$, it was immediately immersed into the coagulation bath containing $20 \%$ aqueous ethanol. The porous PVDF film was formed by the diffusion of DMAc from the solvent phase (the polymer solution) to the non-solvent phase (the coagulation bath). The quadrate modified PVDF film $(50 \times 50 \times 0.4 \mathrm{~mm})$ was washed with distilled water and conserved in distilled water until it was functionalized with PAA.

\subsection{Preparation of PAA/PVDF film (PP)}

The prepared PVDF films were directly functionalized by in situ polymerization of AA on their surface as follows: (1) the PVDF films were pretreated by soaking in ethanol and UP water for $60 \mathrm{~min}$ and $24 \mathrm{~h}$, respectively; (2) drying the PVDF films at $318 \mathrm{~K}$ for $90 \mathrm{~min}$ and cooling them to 
room temperature ( $298 \mathrm{~K})$; (3) a piece of treated film was immersed in AA polymerization solution for $10 \mathrm{~min}$, then quickly sandwiched by two teflon plates and followed by placing them in a vacuum drying oven at $383 \mathrm{~K}$ for $14 \mathrm{~h}$. The AA polymerization solution for modifying PVDF films was composed of AA ( 49.1 wt\%, monomer), EG ( $2.5 \mathrm{wt} \%$, cross-linking reagent), APS ( $1 \mathrm{wt} \%$, initiator) and UP water. The APS was first dissolved in UP water, then adding AA and EG into the resultant solution in order; (4) after the reaction, the teflon plates were taken out of the vacuum and released, next the PAA functionalized PVDF film was dipped in UP water for 2 days to remove surplus monomers and non-anchored polymers at room temperature, while the UP water was refreshed frequently; (5) the functionalized PVDF film by PAA was dried at $318 \mathrm{~K}$ for $90 \mathrm{~min}$, after which cooled to room temperature for subsequent characterization and NZVI synthesis.

\subsection{Synthesis of PPN hybrid}

In details, the synthesized PAA/PVDF films were firstly immersed into $25 \mathrm{~mL}$ of $\mathrm{NaCl}(2 \mathrm{M})$ in a mixture of ethanol-water $(\mathrm{V}: \mathrm{V}=1: 10)$ in a $\mathrm{pH} 11$ and shaked back and forth at $30 \mathrm{rpm}$ for $12 \mathrm{~h}$ under ambient temperature. After rinsing with UP water to remove the excess $\mathrm{NaCl}$, the film containing - $\mathrm{COONa}$ was then introduced into glass vials containing $50 \mathrm{~mL}$ of $\mathrm{FeSO}_{4} \cdot 7 \mathrm{H}_{2} \mathrm{O}(30,60$, or $120 \mathrm{mM})$ in ethanol-water $(\mathrm{V}: \mathrm{V}=2: 5)$ solutions in a $\mathrm{pH} 4$ with shaking at $30 \mathrm{rpm}$ for $14 \mathrm{~h}$ at room temperature, where $\mathrm{Na}^{+}$was exchanged for $\mathrm{Fe}^{2+}$. Next, the yellowed films were rinsed with UP water again and finally immersed into $40 \mathrm{~mL}$ of $\mathrm{NaBH}_{4}(0.8 \mathrm{M})$ in the mixture of ethanol-water $(\mathrm{V}: \mathrm{V}=$ 1:10) for 40 min to yield NZVI particles supported on the PAA/PVDF film. The process of PVDF film preparation, PPN hybrids synthesis and PPN hybrids regeneration was shown in Figure 1.

\subsection{Batch experiments}

$\mathrm{Cr}(\mathrm{VI})$ removal was conducted in $60 \mathrm{~mL}$ glass vials and each of which contained $50 \mathrm{~mL}$ of $\mathrm{Cr}(\mathrm{VI})$ solution. All experiments were conducted in triplicated under aerobic conditions by shaking back and forth at $150 \mathrm{rpm}$ with a rotary shaker. One piece of PPN hybrid film was loaded into each reaction vial. At regular time intervals (up to $120 \mathrm{~min}$ ), $5 \mathrm{~mL}$ of reaction samples were withdrawn for $\mathrm{Cr}(\mathrm{VI})$ residue analysis with atomic absorption spectrophotometer. An identical procedure was used to remove $\mathrm{Cr}(\mathrm{VI})$ with freshly prepared bare NZVI (namely BN) only for comparison. In addition, parallel blank experiments were also conducted under the same conditions, with one piece of PP film only, to examine whether the adsorption of PP hybrid films would affect the removal of $\mathrm{Cr}(\mathrm{VI})$ or not. Subsequently, a series of degradation experiments were also carried out under different initial concentrations of $\mathrm{Cr}(\mathrm{VI})$ solution and $\mathrm{pH}$ values to optimize the reaction conditions of $\mathrm{Cr}(\mathrm{VI})$ removal by PPN. The removal experiments under different reaction temperatures were used to calculate the activation energies.

\subsection{Characterization}

The surface morphologies of freshly prepared PVDF and modified PVDF films with nanoscale $\mathrm{Fe}^{0}$ particles were scanned by a QANT200F SEM system (FEI Co., USA). The film samples were coated with a thin layer of gold to improve their electrical conductivity prior to being scanned. The Fourier Transform Infrared spectra of the bare PVDF and PAA-functionalized PVDF films were recorded on a Varian 7000 e FTIR with attenuated total reflectance (ATR). Films were dried at $363 \mathrm{~K}$ for $4 \mathrm{~h}$ before testing. All FTIR data of PVDF films were collected using 128 scans at a resolution of $4 \mathrm{~cm}^{-1}$.
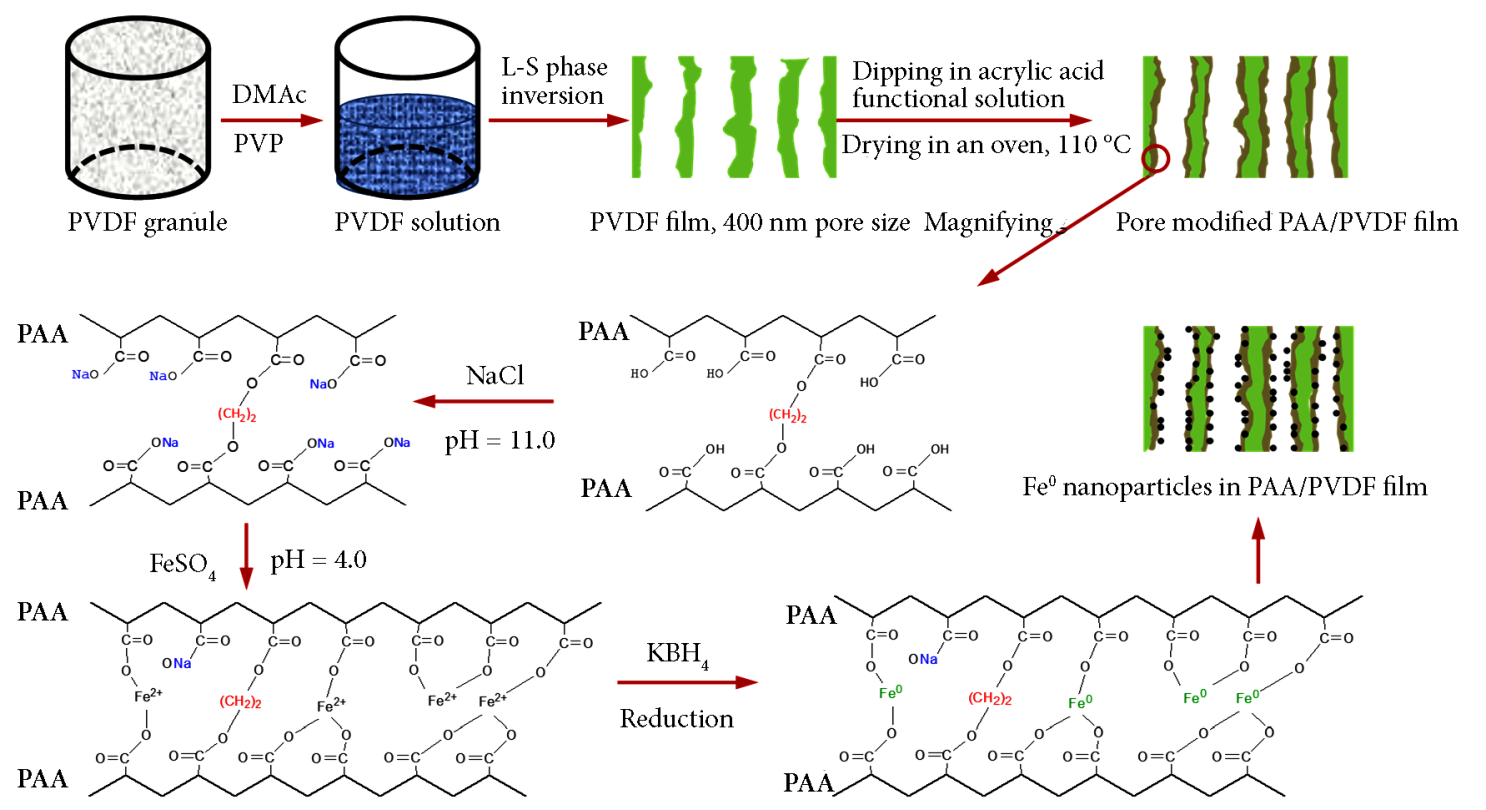

$\mathrm{Fe}^{0}$ nanoparticles in PAA/PVDF film

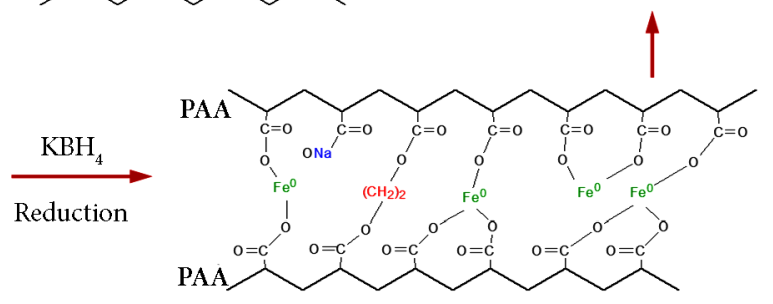

Figure 1. The process of PVDF film preparation and PPN hybrids synthesis 


\section{Results and discussion}

\subsection{Surface functionality of PPN using FTIR spectra}

FTIR-ATR spectroscopy was used to distinguish different organic groups on the PVDF films with PAA and bare PVDF (Figure 2). Absorption peaks at $2800-3100 \mathrm{~cm}^{-1}$ assigned to the hydroxyl group stretching and vibration modes of $-\mathrm{COOH}$ appeared in the spectra of the PAA

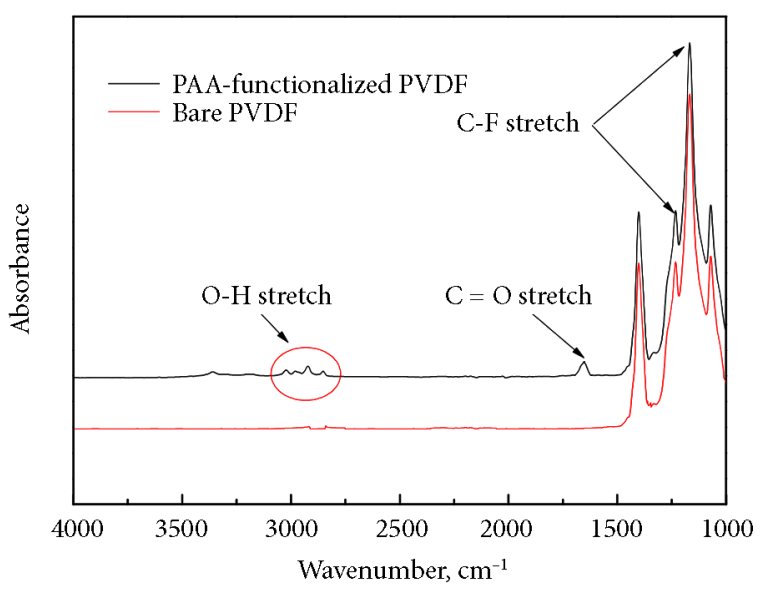

Figure 2. FTIR spectrum for bare and PAA-functionalized PVDF films
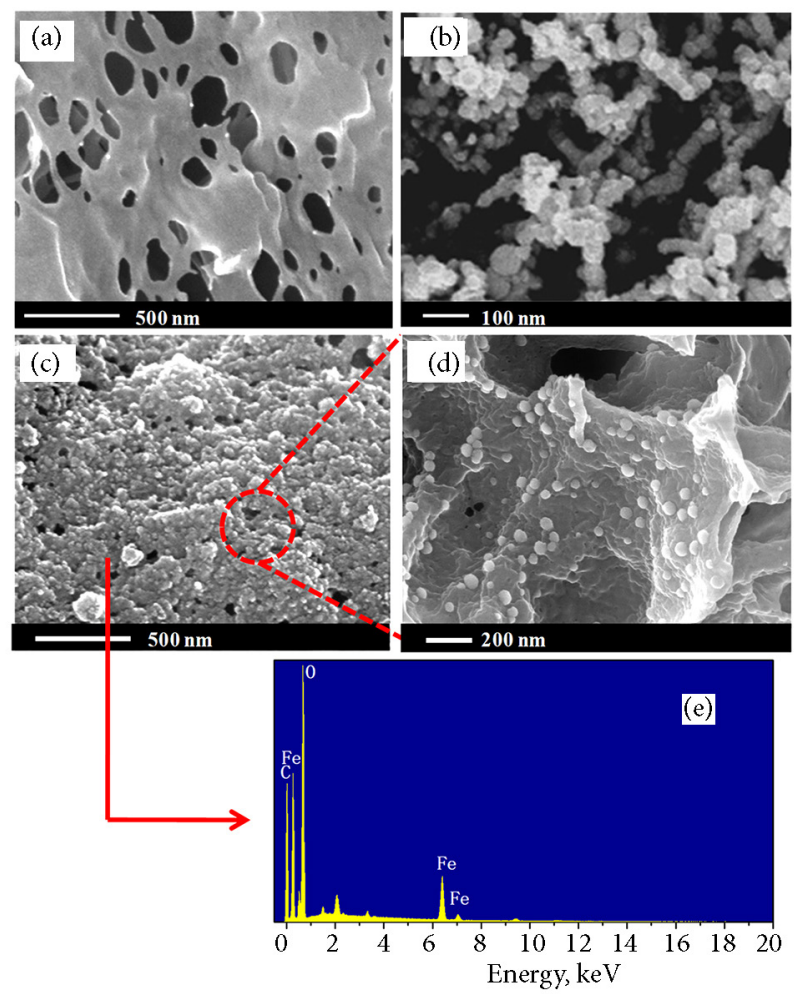

Figure 3. SEM images of PAA/PVDF film surface (a),

NZVI particles before immobilization on the film surface (b), NZVI particles supported on PAA/PVDF films (c); high-magnification of modified PVDF film containing nanoscale $\mathrm{Fe}^{0}$ particles (d), and electron diffusion spectroscopy elemental analysis (e) modified PVDF films. The FT-IR spectra also showed that the $1680 \mathrm{~cm}^{-1}$ absorption peak of the film after PAA functionalized was appeared obviously, which is not present in the spectrum for the bare PVDF film. This peak is attributed to the presence of $\mathrm{C}-\mathrm{O}$ bond stretching in carboxylic acid groups. The existence of the above two kinds of peaks on the PAA modified PVDF films indicating successful PAA immobilization within the functionalized film. Hence, the film hydrophilicity was controlled better because that AA reacted with the hydroxyl groups on the modified film. The absorption peaks at $1140-1280 \mathrm{~cm}^{-1}$ were found to be intense both in the bare PVDF film and modified PVDF (Dai et al. 2014), which were assigned to $\mathrm{C}-\mathrm{F}$ bond stretching vibrations in PVDF.

\subsection{PVDF Surface coverage of NZVI particles in SEM images}

The surface morphologies of freshly prepared PAA/PVDF film, nanoscale $\mathrm{Fe}^{0}$ particles before immobilization on the film surface, nanoscale $\mathrm{Fe}^{0}$ particles supported on PAA/ PVDF film, and high-magnification of modified PVDF film containing NZVI particles are shown in Figure 3. The PAA/PVDF film (Figure 3a) showed great porosity with a highly nonuniform porous microstructure (100-400 nm) by the phase inversion process and grooves are obtained. As observed in SEM image of the porous film surface, after being modified by PAA, the PAA layer did not diminish the surface pore size anymore comparing with PVDF film. The SEM image of nanoscale $\mathrm{Fe}^{0}$ particles before immobilization on the film surface is shown in Figure $3 \mathrm{~b}$. Compared with immobilized NZVI, severe aggregation of unimmobilized NZVI could be found. Nanoscale $\mathrm{Fe}^{0}$ particles were immobilized on the surface (Figure 3c) of PAA/ PVDF film, indicating that PAA was able to transport the NZVI into the pores of the PVDF film and increase the $\mathrm{Fe}^{0}$ loading. An inspection of the particle size by SEM at a higher magnification showed that the NZVI were well immobilized on the surface of the support even in the porous. Therefore, the PAA/PVDF film fresh prepared in this study is considered to be a good matrix for immobilizing nanoscale $\mathrm{Fe}^{0}$ particles. Simultaneously, electron diffusion spectroscopy (EDS) was employed to analyze the surface element composition of the PPN. As shown in Figure 3e, NZVI were found to be successfully immobilized on the PAA/PVDF film.

\subsection{Removal of $\mathrm{Cr}(\mathrm{VI})$ by various materials}

The typical removal profiles of $\mathrm{Cr}(\mathrm{VI})$ against time on $\mathrm{PP}$, $\mathrm{BN}$ and PPN materials are depicted in Figure 4. In the absence of any materials, no measurable Cr(VI) loss was observed. However, the residual concentration of $\mathrm{Cr}(\mathrm{VI})$ steadily decreased when PPN hybrid were introduced into the solutions, indicating that nanoscale $\mathrm{Fe}^{0}$ particles were responsible for all the losses of $\mathrm{Cr}(\mathrm{VI})$. For example, more than $96 \%$ of $\mathrm{Cr}(\mathrm{VI})$ was removed by PPN3 within $120 \mathrm{~min}$ in a solution of $\mathrm{pH} 3.88$. This was the maximum 
removal of $\mathrm{Cr}(\mathrm{VI})$ that could be obtained for PPN hybrid under the conditions. Comparatively, only $44 \%$ of $\mathrm{Cr}(\mathrm{VI})$ was reduced using $7 \mathrm{mg}$ of $\mathrm{BN}$ under the similar conditions, which was lower than that by PPN1 only containing $3.22 \mathrm{mg}$ of NZVI. This implies that in comparison to $\mathrm{BN}$, a smaller amount of NZVI immobilized on PP could perform the same removal efficacy in a shorter period of time, thus saving time as well as materials. The superior removal characteristics of PPN over BN may be ascribed to the fact that, the PP hybrid films with tiny nano-reactors as support materials, i.e., the charged -COO- groups of PAA gels inside PVDF films, did control NZVI agglomeration, thus enhancing the reactivity of PPN hybrid toward $\mathrm{Cr}(\mathrm{VI})$. The change in $\mathrm{Cr}(\mathrm{VI})$ reduction with varying $\mathrm{Fe}$ loadings indicated that there was an increase in the removal with an increase in the loading of NZVI embedded in PPN. In the case of PPN hybrids, the $\mathrm{Cr}(\mathrm{VI})$ removal percentage increased sharply from $0 \mathrm{~min}$ to $20 \mathrm{~min}$, while

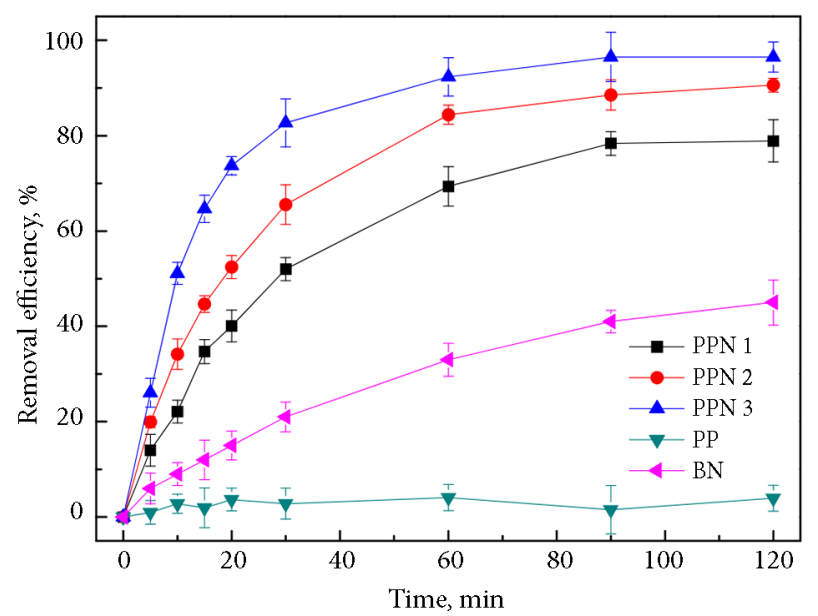

Figure 4. Removal of $\mathrm{Cr}(\mathrm{VI})$ by $\mathrm{PP}, \mathrm{PPN}$, and $\mathrm{BN}$. The $\mathrm{Fe}^{0}$ loadings of PPN1, PPN2, and PPN3 are 3.22, 4.85 and $6.36 \mathrm{mg}$, respectively, and the dosage of $\mathrm{BN}$ is $7 \mathrm{mg}$ $\left(\mathrm{pH}=3.88, \mathrm{C}_{\mathrm{Cr}(\mathrm{VI})}=20 \mathrm{mg} \mathrm{L}^{-1}\right)$

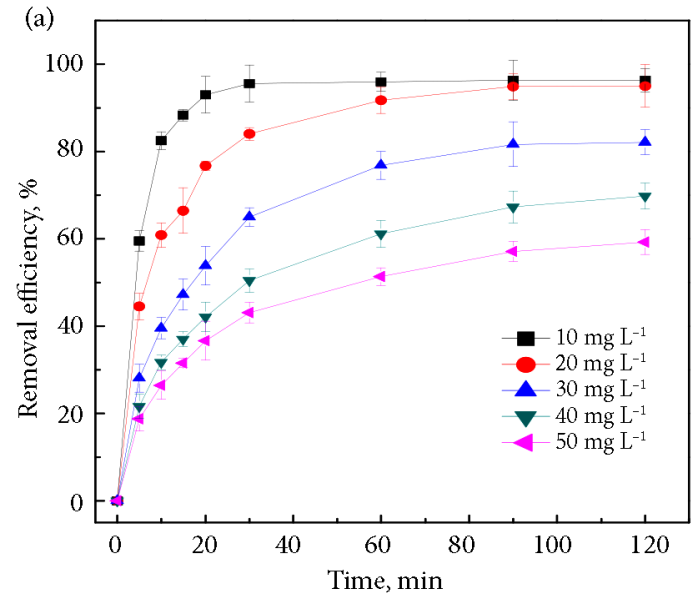

increased at a slow pace beyond $20 \mathrm{~min}$. This is because within a reaction time of $20 \mathrm{~min}$, PPN could supply abundant reactive sites for $\mathrm{Cr}(\mathrm{VI})$ reduction. However, beyond $20 \mathrm{~min}$, such reactive sites would be covered by the iron hydroxides or oxides formed on the surface of PPN during the reaction, thus resulting in declined efficacy of $\mathrm{Cr}(\mathrm{VI})$ reduction by PPN. Additionally, it was also found that the PP hybrids showed little adsorption of $\mathrm{Cr}(\mathrm{VI})$ at less than $4 \%$ after $120 \mathrm{~min}$, which indicating the sorption of PP hybrid films did not contribute to the removal of $\mathrm{Cr}(\mathrm{VI})$.

\subsection{Influencing factors}

For further investigation of the effects on the removal efficiency of $\mathrm{Cr}(\mathrm{VI})$ by PPN hybrids, initial concentration of $\mathrm{Cr}(\mathrm{VI})$ and solution $\mathrm{pH}$ were also examined (Figure 5). Figure 5 a depicts the effect of initial $\mathrm{Cr}(\mathrm{VI})$ concentration on the removal of $\mathrm{Cr}(\mathrm{VI})$ in a range of $10-50 \mathrm{mg} \mathrm{L}^{-1}$. Generally, the removal efficiency of $\mathrm{Cr}(\mathrm{VI})$ increases with the decrease of the initial $\mathrm{Cr}(\mathrm{VI})$ concentration $\mathrm{C}_{0}$, which is mainly responsible for the increase of total available active sites for $\mathrm{Cr}(\mathrm{VI})$ removal with the decreasing concentration of $\mathrm{Cr}(\mathrm{VI})$, thereby leading to higher reaction efficiency. For example, the removal efficiency of $\mathrm{Cr}(\mathrm{VI})$ by PPN2 increased from $59.26 \%$ to $96.32 \%$ within $120 \mathrm{~min}$ in a $\mathrm{pH}$ 3.88 reaction solution when the $\mathrm{C}_{0}$ of $\mathrm{Cr}(\mathrm{VI})$ decreased from $50 \mathrm{mg} \mathrm{L}^{-1}$ to $10 \mathrm{mg} \mathrm{L}^{-1}$. The effect of solution $\mathrm{pH}$ on the reaction is shown in Figure 5b. Obviously, the removal efficiency of $\mathrm{Cr}(\mathrm{VI})$ by PPN increased with the decreased initial $\mathrm{pH}$. For instance, the removal of $\mathrm{Cr}(\mathrm{VI})$ increased when solution $\mathrm{pH}$ decreased from 9.21 to 3.88 . This is due to that the active species like $\mathrm{H}^{*}$ will be consumed when $\mathrm{Cr}(\mathrm{VI})$ was reduced by PPN. Decreasing initial solution $\mathrm{pH}$ is beneficial to the corrosion reaction of $\mathrm{Fe}^{0}$ with water (i.e., the formation of $\mathrm{H}^{*}$ species) and making against the formation of passive ferrous oxide/hydroxide, thus both the needed reactant (i.e., active hydrogen) and reactive sites for $\mathrm{Cr}(\mathrm{VI})$ removal were supplied, therefore improving the removal efficiency of $\mathrm{Cr}(\mathrm{VI})$.

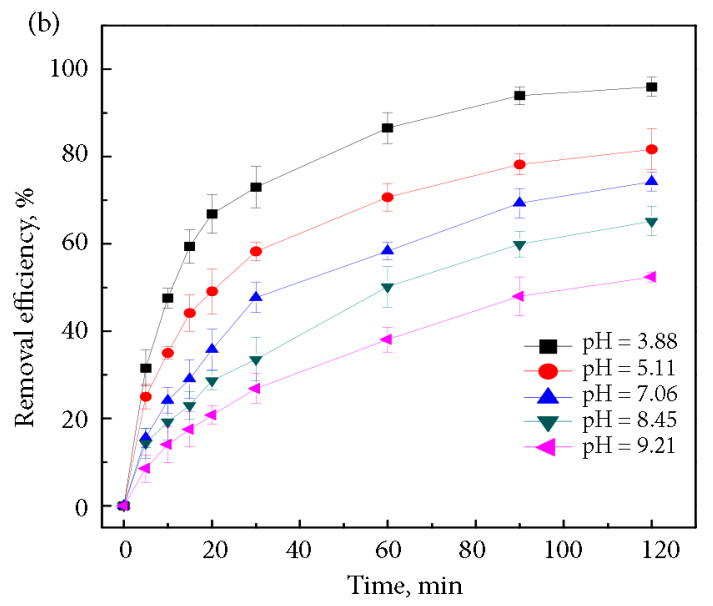

Figure 5. Removal of (a) various initial concentrations of $\mathrm{Cr}(\mathrm{VI})$ by PPN2 ( $\mathrm{pH}=3.88$, temperature $298 \mathrm{~K}$ ) and

(b) $20 \mathrm{mg} \mathrm{L}^{-1}$ of $\mathrm{Cr}(\mathrm{VI})$ by PPN2 under various $\mathrm{pH}$ values (temperature $298 \mathrm{~K}$ ). Other reaction conditions: volume $50 \mathrm{~mL}$ and reaction time $120 \mathrm{~min}$. 


\subsection{Stability and reusability of PPN}

There is another important concern for NZVI-centered remediation except how to inhibit its aggregation and improve its mobility during synthesis, which is how to avoid its potential release into ecosystem and recover it using simple regeneration procedure over the whole course of its application. It's necessary and practical to recycler and regenerate the PPN hybrid for evaluating the long-term performance of PPN hybrid for environmental remediation and reducing the cost of PVDF film. Briefly, the aged PPN was first immersed in UP water for $12 \mathrm{~h}$, while the UP water was refreshed frequently. Then the PPN hybrid was dried at $313 \mathrm{~K}$ for $60 \mathrm{~min}$. Subsequently, the cooled PPN was dipped into $40 \mathrm{~mL}$ of $\mathrm{KBH}_{4}(0.8 \mathrm{M}$, the mixture of ethanol-water $(1: 10, \mathrm{v} / \mathrm{v}))$ prepared for $40 \mathrm{~min}$, followed by washing it with UP water for 3 times. After that, the regenerated PPN hybrids were used to remove $\mathrm{Cr}(\mathrm{VI})$ from water. The removal efficiency of $\mathrm{Cr}(\mathrm{VI})$ by

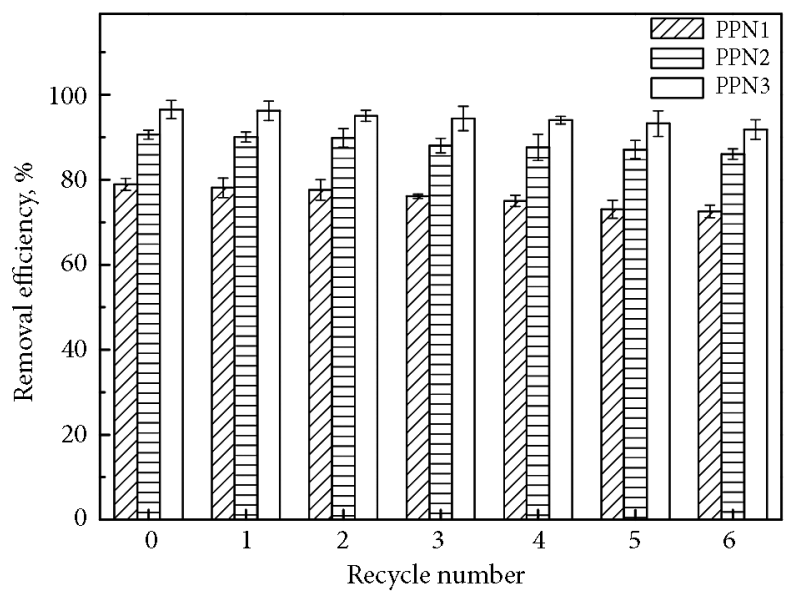

Figure 6. $\mathrm{Cr}(\mathrm{VI})$ removal with recycle numbers for the regenerated PPN. Reaction conditions: $50 \mathrm{~mL}$ of $20 \mathrm{mg} \mathrm{L}^{-1}$ $\mathrm{Cr}(\mathrm{VI})$ solution, $\mathrm{pH}=3.88$, reaction time $120 \mathrm{~min}$, and solution temperature $298 \mathrm{~K}$

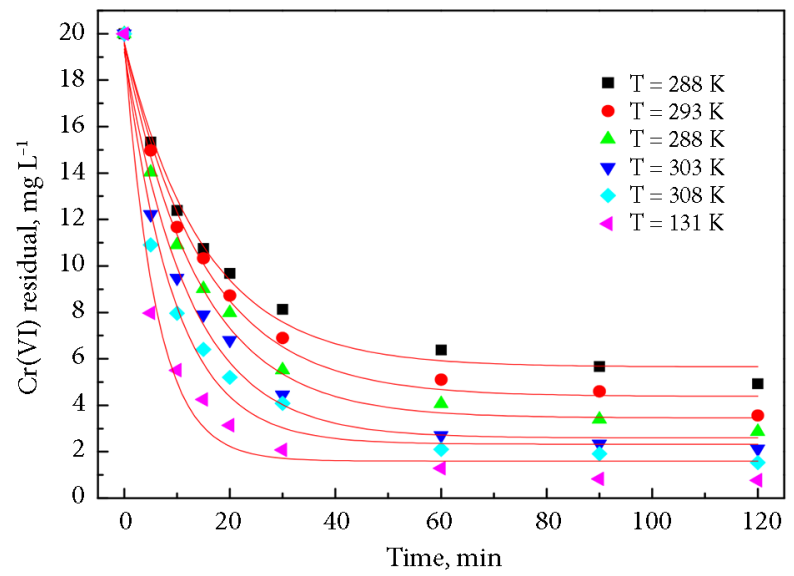

Figure 7. Removal of Cr(VI) by PPN2 at different temperatures. Reaction conditions: $50 \mathrm{~mL}$ of $20 \mathrm{mg} \mathrm{L}^{-1} \mathrm{Cr}(\mathrm{VI})$ solution, $\mathrm{pH}=3.88$, and reaction time $120 \mathrm{~min}$. Lines represent the two-parameter pseudo-first-order decay model regenerated PPN hybrids in each cycle is shown in Figure 6. Obviously, the reactivity of the regenerated PPN hybrids toward $\mathrm{Cr}(\mathrm{VI})$ was not appreciably deteriorated after 6-cycle use compared with that of freshly prepared ones, suggesting that the hybrid PPN with insignificant loss of reactivity retained most of the capacity for supporting nanoscale iron particles after being renewed. May be it's potentially employed to remove $\mathrm{Cr}(\mathrm{VI})$ from aqueous environment during its long-term application.

\subsection{Reaction kinetics and pathways}

Evaluating reaction kinetics of NZVI-contaminate system is a considerable much aspect to well understand the application of NZVI in environment. So variation of experimental factors of reaction temperature indicated that $\mathrm{Cr}(\mathrm{VI})$ removal by NZVI could be optimized for effective transformation of $\mathrm{Cr}(\mathrm{VI})$ in aqueous solution. Some references reported that the reaction of pollutants with NZVI could be described by a first-order or pseudo-firstorder kinetics (Jiang et al. 2012; Fang et al. 2011b, 2011c). However, some other studies indicated that a two/threeparameter pseudo-first-order decay model could well describe the above reaction process, because it took the loss of available reactive sites and presence of nonreactive pollutants into account (Shu et al. 2007, 2010). In order to have in-depth understanding of the reactive process and kinetics, batch experiments of $\mathrm{Cr}(\mathrm{VI})$ removal by PPN2 was carried out under different temperatures (Figure 7). On the basis of the removal profiles of $\mathrm{Cr}(\mathrm{VI})$ in current study, the first-order or pseudo-first-order kinetics model was found doesn't provide the best fit with the experimental data the removal of $\mathrm{Cr}(\mathrm{VI})$ over PPN as we see that the $\mathrm{Cr}(\mathrm{VI})$ in solution generally experienced a fast decline within the first $20 \mathrm{~min}$ and then gradually level off at a relatively constant concentration, indicating the presence of nonreactive $\mathrm{Cr}(\mathrm{VI})$ in the reaction solution. Considering the residual nonreactive $\mathrm{Cr}(\mathrm{VI})$, a two-parameter pseudo-first-order decay model was used to describe the reaction kinetics in this study:

$$
C_{t}=C_{\text {ultimate }}+\left(C_{0}-C_{\text {ultimate }}\right) \times \exp (-k t),
$$

where $C_{t}$ stands for the $\mathrm{Cr}(\mathrm{VI})$ concentration $\left(\mathrm{mg} \mathrm{L}^{-1}\right)$ in solution at reaction time $t$; $C_{\text {ultimate }}$ represents the concentration of nonreactive $\mathrm{Cr}(\mathrm{VI})\left(\mathrm{mg} \mathrm{L}^{-1}\right)$ in solution at infinite time in this study; $C_{0}$ is the initial concentration of $\mathrm{Cr}(\mathrm{VI})\left(\mathrm{mg} \mathrm{L}^{-1}\right)$; and $k$ represents the reaction rate constant. The values of $C_{\text {ultimate }}, k$ calculated, and other conditions are given in Table 1. Obviously, the two-parameter pseudo-first-order kinetics model provides the best fit with the experimental data, and the $R^{2}$ are ranged from 0.9265 to 0.9868 . A high $k$ with decrease of $C_{\text {ultimate }}$ indicates that the $\mathrm{Cr}(\mathrm{VI})$ can be effectively removed by PPN. Such a kinetics model for the reaction is reasonable, which might be attributed mainly to the reactive sites provided by PPN were not necessarily excessive and suffered a corresponding loss over the removal process of $\mathrm{Cr}(\mathrm{VI})$. 
To reveal the control step of the whole reaction, activation energy of a certain chemical reaction was investigated. It has been shown that diffusion controlled reaction usually has relatively low activation energy $\left(8-21 \mathrm{~kJ} \mathrm{~mol}^{-1}\right)$, while the surface-control reactions have relatively higher activation energy $\left(>29 \mathrm{~kJ} \mathrm{~mol}^{-1}\right)$ in previous study. Here a manipulated Arrhenius equation was introduced to describe the relationship between the $k$ and temperature according to the $k$ data obtained from the slope of the fitting line under different temperatures.

$$
\ln k=-\frac{E_{a}}{R T}+\ln A,
$$

where $E_{a}$ represents the activation energy $\left(\mathrm{kJ} \mathrm{mol}^{-1}\right), A$ represents a frequency factor, $R$ represents the ideal gas constant $(\mathrm{kJ} / \mathrm{mol} \mathrm{K})$, and $T$ represents the reaction temperature $(\mathrm{K})$. Thus, a linear correlation will be resulted from a plot of $\ln k$ versus $1 / T$ according to Eq. (2). Figure 8 shows the plot of $\ln k$ versus $1 / T$ for $\mathrm{Cr}(\mathrm{VI})$ removal by PPN2. The activation energies (gained from the slops $(\mathrm{Ea} / \mathrm{R})$ ) of $\mathrm{Cr}(\mathrm{VI})$ by PPN2 was $35.17 \mathrm{~kJ} \mathrm{~mol}^{-1}$, suggesting that the $\mathrm{Cr}(\mathrm{VI})$ removal by PPN2 can be considered as a surface controlled chemical reaction. Conversely, the activation energy of $\mathrm{Cr}(\mathrm{VI})$ reduction with pristine NZVI was $46.31 \mathrm{~kJ} \mathrm{~mol}^{-1}$, indicating that the NZVI supported by PAA/PVDF films result in a lower activation energy, and that a faster chemical process during the $\mathrm{Cr}(\mathrm{VI})$ reduction by pristine NZVI can be anticipated through the approach of $\mathrm{Cr}(\mathrm{VI})$ immobilization with PAA/PVDF films.

It's well known that the removal of heavy metals by NZVI is a surface-mediated process. Such surface-mediate process as $\mathrm{PPN}-\mathrm{Cr}(\mathrm{VI})$ reaction also involves several steps as follows (Figure 9): (1) diffusion of $\mathrm{Cr}(\mathrm{VI})$ molecules into PPN surface, (2) adsorption onto reactive sites provided by PPN, (3) electrons directly or $\mathrm{H}^{*}$ species indirectly via the oxidation of NZVI with $\mathrm{H}_{2} \mathrm{O}$ inducing the chemical reaction, and (4) diffusion of products from reactive PPN.

\section{Conclusions}

Nanoscale zero-valent iron particles (NZVI) were successfully immobilized in the PAA/PVDF film (PPN) for removal of $\mathrm{Cr}(\mathrm{VI})$. SEM characterization of PPN indicates that the synthesized nanoscale zero-valent iron particles were homogeneously dispersed in the film. The PPN

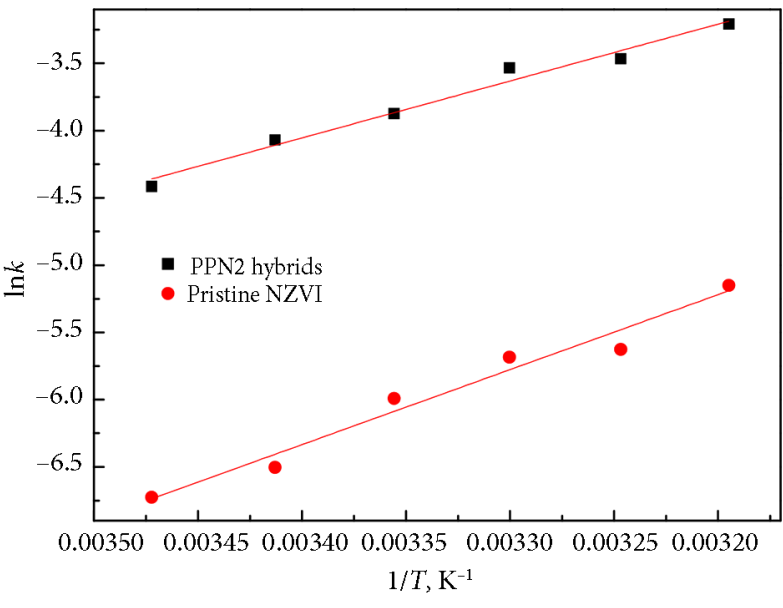

Figure 8. Arrhenius plot for the estimation of activation energy: $\mathrm{Cr}(\mathrm{VI})$ removal by PPN2 hybrids and pristine NZVI

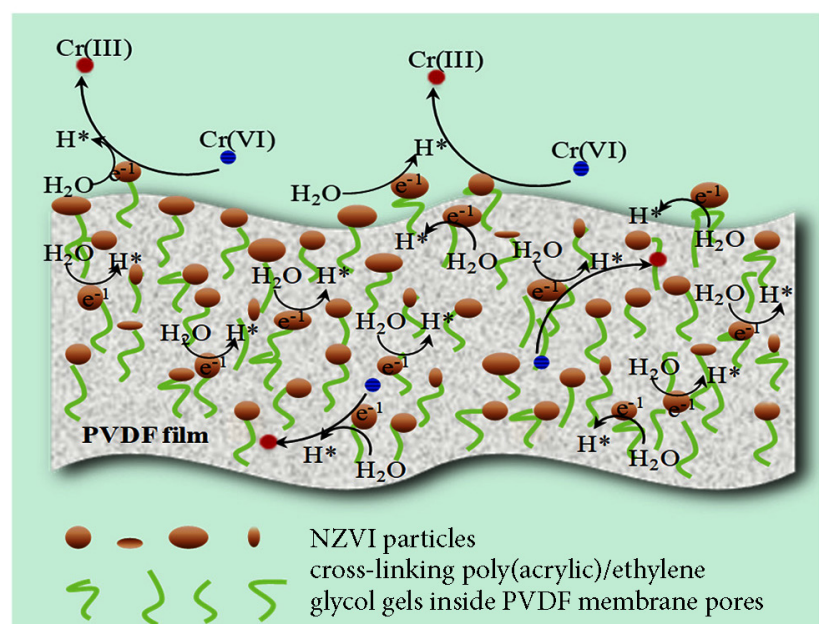

Figure 9. Conceptual model for possible removal pathways of $\mathrm{Cr}(\mathrm{VI})$ by PPN

hybrids demonstrated the highest removal efficiency of $\mathrm{Cr}(\mathrm{VI})$ removal with different materials (PP, PPN and BN). The experimental results show that only $44 \%$ of $\mathrm{Cr}(\mathrm{VI})$ was removed by using $7 \mathrm{mg}$ of unimmobilized NZVI under the same reaction conditions, which was lower than that by PPN1 only containing $3.22 \mathrm{mg}$ of NZVI. Comparing with the pristine NZVI, activation energies of PPN

Table 1. Fitted data for the removal of $\mathrm{Cr}(\mathrm{VI})$ by PPN using a two-parameter pseudo-first-order decay kinetics model

\begin{tabular}{|c|c|c|c|c|c|c|}
\hline$C_{0}\left(\mathrm{mg} \mathrm{L}^{-1}\right)$ & Initial $\mathrm{pH}$ & Temp. $(\mathrm{K})$ & Removal $(\%)$ & $C_{\text {ultimate }}\left(\mathrm{mg} \mathrm{L}^{-1}\right)$ & $k\left(\mathrm{~min}^{-1}\right)$ & $R^{2}$ \\
\hline 20 & 3.88 & 288 & 75.33 & 4.934 & 0.0121 & 0.9868 \\
\hline 20 & 3.88 & 293 & 82.21 & 3.558 & 0.0171 & 0.9716 \\
\hline 20 & 3.88 & 298 & 85.69 & 2.862 & 0.0208 & 0.9731 \\
\hline 20 & 3.88 & 303 & 89.36 & 2.128 & 0.0292 & 0.9591 \\
\hline 20 & 3.88 & 308 & 92.30 & 1.540 & 0.0313 & 0.9265 \\
\hline 20 & 3.88 & 313 & 96.15 & 0.770 & 0.0405 & 0.9805 \\
\hline
\end{tabular}


are calculated to be $35.17 \mathrm{~kJ} \mathrm{~mol}^{-1}$, indicating that $\mathrm{Cr}(\mathrm{VI})$ reduction process with $\mathrm{PPN}$ is a surface-controlled chemical reaction, and the NZVI supported by PAA/PVDF films result in a lower activation energy. Over all, the PPN hybrids exhibited high reactivity, excellent stability and reusability for $\mathrm{Cr}(\mathrm{VI})$ removal. Further studies revealed that decreasing initial concentration of $\mathrm{Cr}(\mathrm{VI})$, increasing reaction temperature and decreasing $\mathrm{pH}$ value accelerated the removal of $\mathrm{Cr}(\mathrm{VI})$ from aqueous solution. A two-parameter pseudo-first-order model was provided to analyze the reaction kinetics of $\mathrm{Cr}(\mathrm{VI})$ removal over PPN under various conditions. This study suggests that NZVIPVDF hybrid possessing excellent performance may be a promising functional material for treatment of $\mathrm{Cr}(\mathrm{VI})$ contaminated wastewater.

\section{Acknowledgements}

This research is supported by the National Nature Science Foundation of China (NSFC, No.51368025, and No. 51068011).

\section{References}

Bhattacharya, M.; Dutta, S. K.; Sikder, J.; Mandal, M. K. 2014. Computational and experimental study of chromium (VI) removal in direct contact membrane distillation, Journal of Membrane Science 450: 447-456.

https://doi.org/10.1016/j.memsci.2013.09.037

Byun, Y. J.; Kim, J. H.; Kim, S. S. 2013. Surface modification of PVDF membranes for water treatment via hydrophilic thermal cross-linking method, Desalination and Water Treatment 51(25-27): 5371-5378.

https://doi.org/10.1080/19443994.2013.768812

Cao, J.; Zhang, W. X. 2006. Stabilization of chromium ore processing residue (COPR) with nanoscale iron particles, Journal of Hazardous Materials 132(2-3): 213-219. https://doi.org/10.1016/j.jhazmat.2005.09.008

Chen, D.; Yang, K.; Wang, H.; Zhou, J.; Zhang, H. 2015. Cr(VI) removal by combined redox reactions and adsorption using pectin-stabilized nanoscale zero-valent iron for simulated chromium contaminated water, RSC Advances 5(80): 65068-65073.

https://doi.org/10.1039/C5RA10573K

Dai, J.; Xiao, K.; Dong, H.; Liao, W.; Tang, X.; Zhang, Z.; Cai, S. 2014. Preparation of $\mathrm{Al}_{2} \mathrm{O}_{3} / \mathrm{PU} / \mathrm{PVDF}$ composite membrane and performance comparison with PVDF membrane, PU/ PVDF blending membrane, and $\mathrm{Al}_{2} \mathrm{O}_{3}$ /PVDF hybrid membrane, Desalination and Water Treatment 57(2): 487-494. https://doi.org/10.1080/19443994.2014.967308

Dong, H.; Xiao, K.; Li, X.; Wang, Z.; Guo, S. 2013. Preparation of $\mathrm{PVDF} / \mathrm{Al}_{2} \mathrm{O}_{3}$ hybrid membrane via alkaline modification and chemical coupling process, Desalination and Water Treatment 51(19-21): 3800-3809.

https://doi.org/10.1080/19443994.2013.782086

Fang, X.; Li, J.; Li, X.; Sun, X.; Shen, J.; Han, W.; Wang, L. 2015. Polyethyleneimine, an effective additive for polyethersulfone ultrafiltration membrane with enhanced permeability and selectivity, Journal of Membrane Science 476: 216-223. https://doi.org/10.1016/j.memsci.2014.11.021

Fang, Z.; Chen, J.; Qiu, X.; Qiu, X.; Cheng, W.; Zhu, L. 2011 b. Effective removal of antibiotic metronidazole from water by nanoscale zero-valent iron particles, Desalination 268(1-3): 60-67.

https://doi.org/10.1016/j.desal.2010.09.051

Fang, Z.; Qiu, X.; Chen, J.; Qiu, X. 2011c. Debromination of polybrominated diphenyl ethers by $\mathrm{Ni} / \mathrm{Fe}$ bimetallic nanoparticles: influencing factors, kinetics, and mechanism, Journal of Hazardous Materials 185(2-3): 958-969.

https://doi.org/10.1016/j.jhazmat.2010.09.113

Fang, Z.; Qiu, X.; Huang, R.; Qiu, X.; Li, M. 2011a. Removal of chromium in electroplating wastewater by nanoscale zerovalent metal with synergistic effect of reduction and immobilization, Desalination 280(1 - 3): 224-231.

Horzum, N.; Demir, M. M.; Nairat, M.; Shahwan, T. 2013. Chitosan fiber-supported zero-valent iron nanoparticles as a novel sorbent for sequestration of inorganic arsenic, RSC Advances 3(21): 7828-7837.

https://doi.org/10.1039/c3ra23454a

Jiang, Z.; Zhang, S.; Pan, B.; Wang, W.; Wang, X.; Lv, L.; Zhang, W.; Zhang, Q. 2012. A fabrication strategy for nanosized zero valent iron (nZVI)-polymeric anion exchanger composites with tunable structure for nitrate reduction, Journal of Hazardous Materials 233-234: 1-6. https://doi.org/10.1016/j.jhazmat.2012.06.025

Kim, H.; Hong, H. J.; Lee, Y. J.; Shin, H. J.; Yang, J. W. 2008. Degradation of trichloroethylene by zero-valent iron immobilized in cationic exchange membrane, Desalination 223(1-3): 212-220. https://doi.org/10.1016/j.desal.2007.03.015

Kim, M. K.; Shanmuga Sundaram, K.; Anantha Iyengar, G.; Lee, K. P. 2015. A novel chitosan functional gel included with multiwall carbon nanotube and substituted polyaniline as adsorbent for efficient removal of chromium ion, Chemical Engineering Journal 267: 51-64. https://doi.org/10.1016/j.cej.2014.12.091

Li, S.; Li, T.; Xiu, Z.; Jin, Z. 2010. Reduction and immobilization of chromium(VI) by nano-scale $\mathrm{Fe}^{0}$ particles supported on reproducible PAA/PVDF membrane, Journal of Environmental Monitoring 12(5): 1153-1158. https://doi.org/10.1039/b919909h

Li, X.; Cao, J.; Zhang, W. 2008. Stoichiometry of Cr(VI) immobilization using nanoscale zerovalent iron (nZVI): a study with high-resolution X-Ray photoelectron spectroscopy (HRXPS), Applied Chemistry 47: 2131-2139.

https://doi.org/10.1021/ie061655x

Li, X.; Pang, R.; Li, J.; Sun, X.; Shen, J.; Han, W.; Wang, L. 2013. In situ formation of Ag nanoparticles in PVDF ultrafiltration membrane to mitigate organic and bacterial fouling, Desalination 324: 48-56.

https://doi.org/10.1016/j.desal.2013.05.021

Lin, C. J.; Liou, Y. H.; Lo, S. L. 2009. Supported Pd/Sn bimetallic nanoparticles for reductive dechlorination of aqueous trichloroethylene, Chemosphere 74(2): 314-319.

https://doi.org/10.1016/j.chemosphere.2008.08.046

Ling, L.; Pan, B.; Zhang, W. X. 2015. Removal of selenium from water with nanoscale zero-valent iron: mechanisms of intraparticle reduction of Se(IV), Water Research 71: 274-281. https://doi.org/10.1016/j.watres.2015.01.002

Lv, X.; Xu, J.; Jiang, G.; Tang, J.; Xu, X. 2012. Highly active nanoscale zero-valent iron (nZVI)- $\mathrm{Fe}_{3} \mathrm{O}_{4}$ nanocomposites for the removal of chromium(VI) from aqueous solutions, Journal of Colloid and Interface Science 369(1): 460-469. https://doi.org/10.1016/j.jcis.2011.11.049

Meng, Z.; Liu, H.; Liu, Y.; Zhang, J.; Yu, S.; Cui, F.; Ren, N.; Ma, J. 2011. Preparation and characterization of $\mathrm{Pd} / \mathrm{Fe}$ bimetallic nanoparticles immobilized in PVDF. $\mathrm{Al}_{2} \mathrm{O}_{3}$ membrane for 
dechlorination of monochloroacetic acid, Journal of Membrane Science 372(1-2): 165-171.

https://doi.org/10.1016/j.memsci.2011.01.064

Mu, Y.; Ai, Z.; Zhang, L.; Song, F. 2015b. Insight into core-shell dependent anoxic $\mathrm{Cr}(\mathrm{VI})$ removal with $\mathrm{Fe} @ \mathrm{Fe}_{2} \mathrm{O}_{3}$ nanowires: indispensable role of surface bound Fe(II), ), ACS applied materials \& interfaces 7(3): 1997-2005.

https://doi.org/10.1021/am507815t

$\mathrm{Mu}$, Y.; Wu, H.; Ai, Z. 2015a. Negative impact of oxygen molecular activation on $\mathrm{Cr}(\mathrm{VI})$ removal with core-shell $\mathrm{Fe} @ \mathrm{Fe}_{2} \mathrm{O}_{3}$ nanowires, Journal of Hazardous Materials 298: 1-10. https://doi.org/10.1016/j.jhazmat.2015.05.008

Oh, S. J.; Kim, N.; Lee, Y. T. 2009. Preparation and characterization of $\mathrm{PVDF} / \mathrm{TiO}_{2}$ organic-inorganic composite membranes for fouling resistance improvement, Journal of Membrane Science 345(1-2): 13-20. https://doi.org/10.1016/j.memsci.2009.08.003

Qiu, X.; Fang, Z.; Yan, X.; Cheng, W.; Lin, K. 2013. Chemical stability and toxicity of nanoscale zero-valent iron in the remediation of chromium-contaminated watershed, Chemical Engineering Journal 220: 61-66. https://doi.org/10.1016/j.cej.2012.11.041

Shen, Y. S.; Wang, S. L.; Huang, S. T.; Tzou, Y. M.; Huang, J. H. 2010. Biosorption of $\mathrm{Cr}(\mathrm{VI})$ by coconut coir: spectroscopic investigation on the reaction mechanism of $\mathrm{Cr}(\mathrm{VI})$ with lignocellulosic material, Journal of Hazardous Materials 179(1-3): 160-165. https://doi.org/10.1016/j.jhazmat.2010.02.073

Shih, Y. h.; Hsu, C. y.; Su, Y. f. 2011. Reduction of hexachlorobenzene by nanoscale zero-valent iron: kinetics, $\mathrm{pH}$ effect, and degradation mechanism, Separation and Purification Technology 76(3): 268-274. https://doi.org/10.1016/j.seppur.2010.10.015

Shu, H. Y.; Chang, M. C.; Chen, C. C.; Chen, P. E. 2010. Using resin supported nano zero-valent iron particles for decolora- tion of Acid Blue 113 azo dye solution, Journal of Hazardous Materials 184(1-3): 499-505.

https://doi.org/10.1016/j.jhazmat.2010.08.064

Shu, H. Y.; Chang, M. C.; Yu, H. H.; Chen, W. H. 2007. Reduction of an azo dye acid black 24 solution using synthesized nanoscale zerovalent iron particles, Journal of colloid and interface science 314(1): 89-97. https://doi.org/10.1016/j.jcis.2007.04.071

Wang, X.; Chen, C.; Liu, H.; Ma, J. 2008. Preparation and characterization of PAA/PVDF membrane-immobilized Pd/Fe nanoparticles for dechlorination of trichloroacetic acid, Water Research 42(18): 4656-4664. https://doi.org/10.1016/j.watres.2008.08.005

Xia, Z.; Liu, H., Wang, S.; Meng, Z.; Ren, N. 2012. Preparation and dechlorination of a poly(vinylidene difluoride)-grafted acrylic acid film immobilized with $\mathrm{Pd} / \mathrm{Fe}$ bimetallic nanoparticles for monochloroacetic acid, Chemical Engineering Journal 200-202: 214-223. https://doi.org/10.1016/j.cej.2012.06.056

$\mathrm{Xu}, \mathrm{L}$.; Wang, J. 2011. A heterogeneous Fenton-like system with nanoparticulate zero-valent iron for removal of 4-chloro3-methyl phenol, Journal of Hazardous Materials 186(1): 256-264. https://doi.org/10.1016/j.jhazmat.2010.10.116

Yang, J.; Wang, X.; Zhu, M.; Liu, H.; Ma, J. 2014. Investigation of PAA/PVDF-NZVI hybrids for metronidazole removal: synthesis, characterization, and reactivity characteristics, Journal of Hazardous Materials 264: 269-277. https://doi.org/10.1016/j.jhazmat.2013.11.037

Zaleckas, E.; Paulauskas, V.; Sendžikienè, E. 2013. Fractionation of heavy metals in sewage sludge and their removal using low-molecular-weight organic acids, Journal of Environmental Engineering and Landscape Management 21(3): 189-198. https://doi.org/10.3846/16486897.2012.695734 